\title{
Research on the Status and Countermeasures of Tibet Animal Genetic Resources Conservation
}

\author{
Jing Ouyang ${ }^{1, a}$ \\ ${ }^{1}$ Jiangxi Science \& Technology Normal University, Jiangxi, Nanchang, China, 330013 \\ aemail,
}

Keywords: Status, Countermeasures, Tibet, Animal Genetic Resources, Conservation

\begin{abstract}
Today, the socio-economic gets a rapid development, but as the national GDP increases, it takes a lot of environmental damage and resource exploitation for the price. According to the survey we found that the current number of resources continues to a sharp drop, especially animal genetic resources has been significantly reduced, resulting in reduced carrying capacity of the social environment and it is not conducive to the sustainable development of the country. Tibet is located in northwest of China, there are a large number of animals, species-rich, contains a lot of resources and it is the basis for human survival and also the genetic treasure trove for the future development. However, due to the constraints of traditional thinking and the lack of awareness of animal genetic resources, resulting in many countries consume and waste a lot of resources, hindering the development of humanity. Based on this phenomenon, China must rediscover the importance of the protection of genetic resources, protect Tibet's animal genetic resources as a starting point to study its current situation, propose effective measures combined with practical to protect resources to lay a solid foundation for social development.
\end{abstract}

\section{Introduction}

Animal genetic resources is one of the most important types of resources, mainly refers to the genetic material of actual or potential value of this material from a variety of plants, animals and microorganisms among genetic function, which is to ensure that biodiversity the key, the national livestock development base, has a positive effect on human survival and development. As we all know, China's vast land area, the terrain in different regions, the terrain, the environment has a very different, these differences created a variety of organisms, making China the most abundant animal genetic resources, one of the countries. However, due to environmental damage, pollution and human resource implications of action, so that animal genetic resources have been dropped, diversity decreased. Tibet animal large and abundant species and it has long been a national key protected areas, which is why, in the area of animal genetic resources are often destroyed, and even other countries to steal resources. For this phenomenon, we must strengthen our efforts in protecting Tibet's animal resources, clearly the current status of resources, and provide scientific countermeasure protection of genetic resources, to ensure that features biodiversity.

\section{The Current Situation of Tibet Animal Genetic Resources Conservation}

The Situation of Genetic Resources. The characteristics of the resource. Tibet Plateau region is located in China, as the world's largest plateau, known as the "roof of the world" and "third pole of the earth," biologist called "the Kingdom of wildlife." The area is very rich in resources, and unique, special environment created a variety of animal genetic resources, is very gene-rich areas.

Resource Status. Tibet has a vast area of land, features a distinctive climate, many rivers and terrain, lush forests, is to focus on areas of many plants and animals. According to statistics, the region, including more than 2300 kinds of insects, State Key 120 kinds of rare animals, the number of up to 30\% of the country's proportion of the total, 22 species of birds endemic in Tibet, there are more than 50,000 the number of wild yak, black top crane is the only crane survival of animals in the Tibetan Plateau.

Measures for the Protection of Genetic Resources. Laws and regulations. Tibet in the 
protection of animal resources has been introduced in line with their actual characteristics of the "Tibet Autonomous Region Implementation Measures" and "animal immunization" for special environment also promulgated the "Lhasa Lalu Wetland Nature Reserve Management Ordinance."

Wildlife protection. In 1998 China promulgated the "People's Republic of China Wild Animal Protection Law", followed by the development of Tibet, implementation methods, and published a list of affected countries and regional key protected wild animals. At present, Tibet has established 25 wildlife nature reserves, set up black-necked cranes as the main object of protection of the middle reaches of the river valley and the elegant SELINCUO two black-necked crane nature reserve, set up a Tibetan antelope, wild yak, etc. Changtang national Nature Reserve is the main object of protection of the world's largest number of wild herbivores populations. As the home of the Tibetan antelope, Tibetan government protecting its special attention on the illegal killing acts in law formulated strict standards.

\section{The Deficiencies in the Conservation of Tibet Animal Genetic Resources}

First, the Serious Impacts of Climate Change. In recent years, global warming trends continue to strengthen, which animals and plants survive in Tibet brought tremendous impact declining height of Mount Everest, glacier melt slowly. Thus, black top crane is difficult to find edible barley, pollutants also increase, resulting in sharp drop in biodiversity, grew up in the clear lake fish found in the detection of pollution resources actually contain emissions from human activities, vegetation growth slow.

Second, the Living Space Becomes Narrow. Everest in a kind of survival of the snow leopard, the plateau is the most important habitat, but because of human sabotage, resulting in decreasing the number of snow leopards, these animals often suffer invasion, survival increasingly narrow.

Third, Killing is Serious Driven by Economic Interests. Since the 1970s, China's Tibetan antelope is treated as one of the national key protected animals and protected in law. But also because of its precious nature, so a lot of people in the interests of drivers began to cull, some people also sprinkle the drug supply antelope eat and probability of causing animal diseases also put increasing animal genetic resources conservation issues facing a serious situation.

\section{Tibet Animal Genetic Resources Conservation Strategy}

Develop Sound Protection System and Strengthen Illegal Cost. We want to protect fundamental Tibet animal genetic resources to ensure that its diversity, it is necessary to develop a sound institutional system, strict enforcement of law and full enforcement. Specifically, regulations and policies should be targeted, according to local conditions, act upon and implement projects to protect and improve relevant content based on regional characteristics and the real situation in Tibet, develop and make good use of resources, safeguard the legitimate rights and interests of the region. At the same time, but also a clear awareness and protection in an important position of animal genetic resources, adhere to long-term supervision and strict regulation, the overall supervision, coordination of regulation, the development of new regulations to protect, to increase the punishment for illegal workers to upgrade their compliance costs.

Strengthen Excavation, Identification, Evaluation and Information Management of Animal Genetic Resources. Currently, Tibet specializing in animal genetic resources excavation, identification, evaluation and information management are very few, in addition to basic research no one to do it, but for most of the current research projects we are more concerned about some of the most talked about livestock and wildlife to carry out, mainly with the local low level of scientific research has a great relationship. So to strengthen cooperation with the mainland, the relevant personnel grass-roots work of specialized training to explore a variety of special charge of animal resources, the identification, evaluation and information management.

Increase Funding Investment of Animal Genetic Resources Conservation. Animal genetic resources is a major national strategic resource base, is the material basis of social, economic and environmental sustainability, conservation is a costly task, requiring multiple channels to try to raise 
conservation funds. The

In order to strengthen efforts to protect, first of all to increase investment funds. Sources of funding can have several channels First, the government financial input, which is the basis for conservation; second is the support of the international community; the third is social group or individual sponsorship; fourth, the comprehensive development and utilization of genetic resources is active financing conservation.

Reduce Vandalism. Currently, Tibet conservation of animal genetic resources are not in place, on the one hand and investment policy constraints, on the other hand is serious vandalism. For this phenomenon, our country must promote its role in environmental protection, to raise awareness of the conservation of animal genetic resources, to make people understand the relationship between biodiversity resources and future social development. Also confirmed human environmental protection measures to reduce emissions of pollutant discharge to avoid damage to vandalism problem of animal genetic resources as a result.

\section{Conclusion}

All in all, under the background of the development of socialist modernization, we must have a clear understanding of the animal genetic resources protection. Based on the phenomenon of the destruction of animal genetic resources at this stage, we analyze the shortcomings and then carry out a variety of protect measures, research an effective protection measure. Specifically, the Tibet region should combine the actual situation, develop the sound conservation program, strengthen efforts to the all-round protection of animal genetic resources, make a good plan of mining, management, evaluation, etc. to reduce the probability of vandalism and increase punishment efforts to maintain good diversity of plants and animals to achieve harmonious development between man and animal.

\section{References}

[1] Dong Hailong, Zhu Hongyun, Liu Haiping, Rui Yapei. The conservation status of animal genetic resources in Tibet and countermeasures [J] World Agriculture, 2012, 02: 86-90

[2] Xin Shengpeng, Kelsang Dawa. Discussion on Tibetan mastiff genetic resources conservation and development [J] Chinese animal husbandry, 2012, 07: 56-59

[3] Zhu Hongyun, Dong Hailong, Rui Yapei, Liu Haiping. Explore from the legislative perspective Tibet Tibetan local genetic resources conservation [J] Science and Technology Management Research, 2011, 15: 31-35

[4] Xin Jinwei, Zhang Chengfu, Zhang Qiang, Ji Qiumei, Zhong Jincheng, Dawa Lausanne, Kan east. Protection and utilization of genetic resources in Tibet[J]. China Cattle Industry Science, 2010, 06: 59-61

[5] Jin Wei, Zhang Chengfu, Zhang Qiang, Ji Qiumei, Dawa. Protection and use of information and central pull, bell Jincheng Tibetan yak genetic resources [J]. Sichuan Animal Husbandry and Veterinary Medicine, 2010, 12: 38-39

[6] Jin. Tibet Canada measures animal genetic resources conservation and utilization of the work of thinking [J] Chinese animal husbandry, 2013, 24: 37-38. 